\title{
SILDENAFIL UPREGULATES TUMOR NECROSIS FACTOR $\alpha$ PRODUCTION IN PERIPHERAL BLOOD MONONUCLEAR CELLS OF HEALTHY MEN - PRELIMINARY REPORT
}

\author{
BEATA KALETA $^{1 *}$, AGNIESZKA BOGUSKA ${ }^{1}$, JAN BORYSOWSKI $^{1}$ \\ and ANDRZEJ GÓRSKI ${ }^{1}$
}

${ }^{1}$ Department of Clinical Immunology, Transplantation Institute, Medical University of Warsaw, 59 Nowogrodzka St., 02-006 Warsaw, Poland

\begin{abstract}
Sildenafil is a selective type 5 phosphodiesterase (PDE5) inhibitor, commonly used in the treatment of erectile dysfunction (ED) and pulmonary arterial hypertension (PAH). The results of recent studies suggest that this drug modulates function of the immune system. However, only few studies were performed in humans. Therefore, the aim of this study was to investigate the ability of sildenafil to regulate the production of proinflammatory cytokines including tumor necrosis factor alpha (TNF- $\alpha$ ), interleukin (IL)-1 $\beta$ and IL-6 in peripheral blood mononuclear cells (PBMCs) from healthy men. Phorbol myristate acetate (PMA) - stimulated and unstimulated PBMCs from 16 participants were cultured in the absence or presence of sildenafil $(400 \mathrm{ng} / \mathrm{mL}$ and $4 \mu \mathrm{g} / \mathrm{mL}$ ). TNF- $\alpha$, IL- $1 \beta$ and IL- 6 concentrations in culture supernatants were measured by enzyme-linked immunosorbent assay (ELISA). Cell viability was assessed by trypan blue staining. Sildenafil at a concentration of $400 \mathrm{ng} / \mathrm{mL}$ significantly increased TNF- $\alpha$ production in stimulated PBMCs $(\mathrm{p}<0.05)$ but had no effects on IL-1 $\beta$ and IL-6. The drug did not affect PBMCs viability. This is the first report describing such effects of sildenafil in humans.
\end{abstract}

Keywords: cytokines, peripheral blood mononuclear cells, sildenafil, tumor necrosis factor alpha

In recent years, cytokines and inflammation have been implicated in a growing number of diseases, including cancer, type 2 diabetes, cardiovascular and autoimmune disorders (1). Therefore, it is believed that cytokines signaling pathways are potential therapeutic targets for a wide variety of diseases.

Sildenafil, a selective inhibitor of type 5 phosphodiesterase (PDE5), is the most effective and widely used therapy for erectile dysfunction (ED) and pulmonary arterial hypertension (PAH) (2). ED is commonly associated with chronic conditions such as atherosclerosis, hypertension, diabetes, Parkinson's disease, multiple sclerosis and many others (2-4). Sildenafil inhibits PDE5 which contributes to the increase of cyclic guanosine monophosphate-protein (cGMP) level (2). cGMP activates cGMP - dependent protein kinase G (PKG) which is implicated in the regulation of functions of many different cell types (2-4). In addition, the inhibition of cGMP catabolism stimulates inducible nitric oxide synthase (iNOS) and triggers nitric oxide synthase (NOS) phosphorylation, which in turn increases NO levels $(4,5)$.

PDE5 is expressed in various cells, including cardiomyocytes, vascular smooth muscle cells, endothelial and epithelial cells, myometrial cells and ureteral smooth muscle cells (4-6). Recent studies demonstrated that both PDE5 and iNOS are also found in human T lymphocytes, granulocytes, dendritic cells, and macrophages $(5,6)$.

A growing body of evidence shows that sildenafil exerts immunomodulatory effects in animal models, however, only a few studies were conducted in humans (7).

Our previous studies demonstrated that sildenafil decreased the activity of natural killer (NK) cells (8) and downregulated osteopontin (OPN) production in healthy men in vitro (9). Thus, the present study was designed to investigate the effect of this selective PDE5 inhibitor on other pro-inflammatory cytokines (TNF- $\alpha$, IL-1 $\beta$, IL-6) synthesis.

$\bar{*}$ Corresponding author: e-mail: kaletabeata1@gmail.com 


\section{EXPERIMENTAL}

Isolation of peripheral blood mononuclear cells

16 healthy blood donors (men) participated in the study. Venous blood samples were collected into lithium heparin tubes after receiving informed consent. PBMCs were isolated by centrifugation on Histopaque-1077 (Sigma Aldrich). PBMCs were resuspended in RPMI medium (Gibco) supplemented with $2 \mathrm{mM}$ L-glutamine (Sigma), $0.1 \mathrm{mg} / \mathrm{mL}$ gentamycin (KRKA) and 10\% fetal bovine serum (FBS, Gibco).

Culturing of peripheral blood mononuclear cells

PBMCs were seeded at a density of $1 \times 10^{6}$ cells/well in 24-well plates (Greiner CELLSTAR ${ }^{\circledast}$ ). Sildenafil was added to cell cultures at final concentrations of $400 \mathrm{ng} / \mathrm{mL}(0.6 \mu \mathrm{M})$ and $4 \mu \mathrm{g} / \mathrm{mL}(6 \mu \mathrm{M})$. Drug concentration has been selected on the basis of the near therapy doses, according to their pharmacokinetics (Cmax and area under the time-concentration curve, AUC) (10). $400 \mathrm{ng} / \mathrm{mL}$ is a serum level of sildenafil after a single $100 \mathrm{mg}$ oral administration (10). The concentration of $4 \mu \mathrm{g} / \mathrm{mL}$ (10-fold higher than the average therapeutic concentration) was used to check the potential toxic effects on human PBMCs. Control cultures contained an equivalent volume of medium. PBMCs were cultured for 20 hours at $37^{\circ} \mathrm{C}$ in a sterile environment with $5 \% \mathrm{CO}_{2}$ and humidified atmosphere. After the incubation period, phorbol myristate acetate (PMA) and ionomycin (Sigma Aldrich, $50 \mathrm{ng} / \mathrm{mL}$ and $1 \mu \mathrm{g} / \mathrm{mL}$, respectively) were added to wells with PBMCs and PBMCs treated with sildenafil. Control variants (PBMCs and PBMCs with sildenafil) were not stimulated. Next, PBMCs were incubated at $37^{\circ} \mathrm{C}$ in a sterile environment with $5 \% \quad \mathrm{CO}_{2}$ and humidified atmosphere for 4 hours. After the incubation period, culture supernatants were collected and stored at $-80^{\circ} \mathrm{C}$ for TNF- $\alpha$, IL- $1 \beta$ and IL- 6 concentration assessment by enzyme-linked immunosorbent assay (ELISA).

Evaluation of cytokine production by the enzyme-linked immunosorbent assay

To examine the sildenafil-induced TNF- $\alpha$, IL$1 \beta$ and IL- 6 secretion by PBMCs, the concentrations of these cytokines were measured in culture supernatants by ELISA according to the manufacturer's instructions (BD OptEIA ${ }^{\mathrm{TM}}$ Set Human TNF, IL-6, IL-1 $\beta$ BD Biosciences) in duplicates. Chromate 4300 Microplate Reader was used for reading at 450 $\mathrm{nm}$. The results were expressed in $\mathrm{pg} / \mathrm{mL}$.

\section{Cell viability assay}

PBMCs were collected by centrifugation and stained with $0.4 \%$ trypan blue. A number of total and dead cells was counted using a hemocytometer. Values were expressed as a percentage of control culture (100\%).

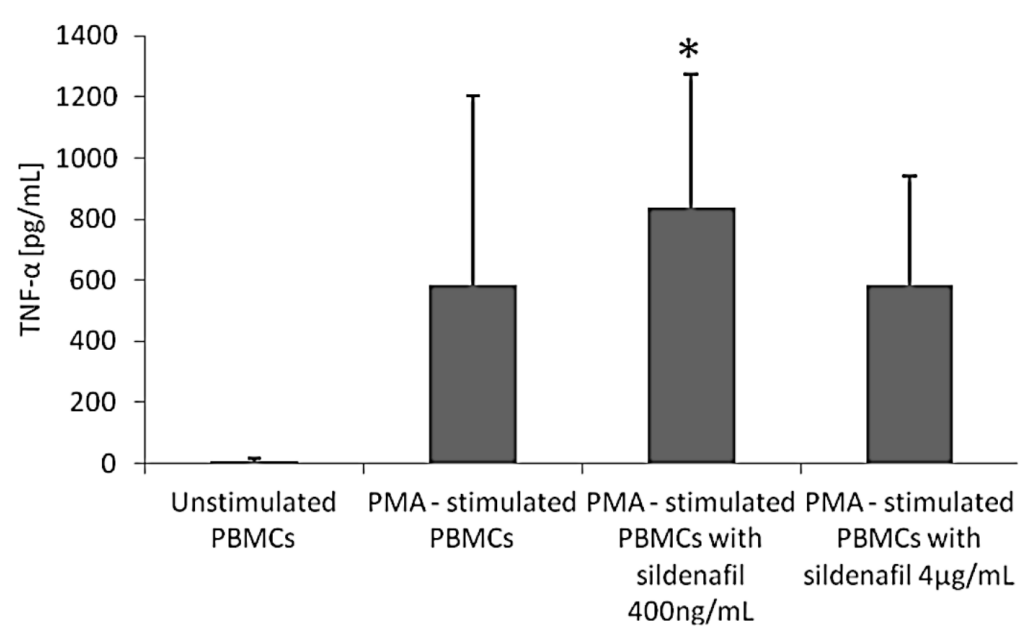

Figure 1. TNF- $\alpha$ concentration in peripheral blood mononuclear cells (PBMCs) supernatants measured by enzyme-linked immunosorbent assay (ELISA, mean \pm standard deviation) after incubation with sildenafil and with or without stimulation with phorbol myristate acetate (PMA) plus ionomycin. Differences were considered statistically significant when $\mathrm{p}<0.05$ for ANOVA test on 16 PBMCs samples. *p $<$ 0.05 between stimulated PBMCs and stimulated PBMCs with sildenafil $400 \mathrm{ng} / \mathrm{mL}$ 


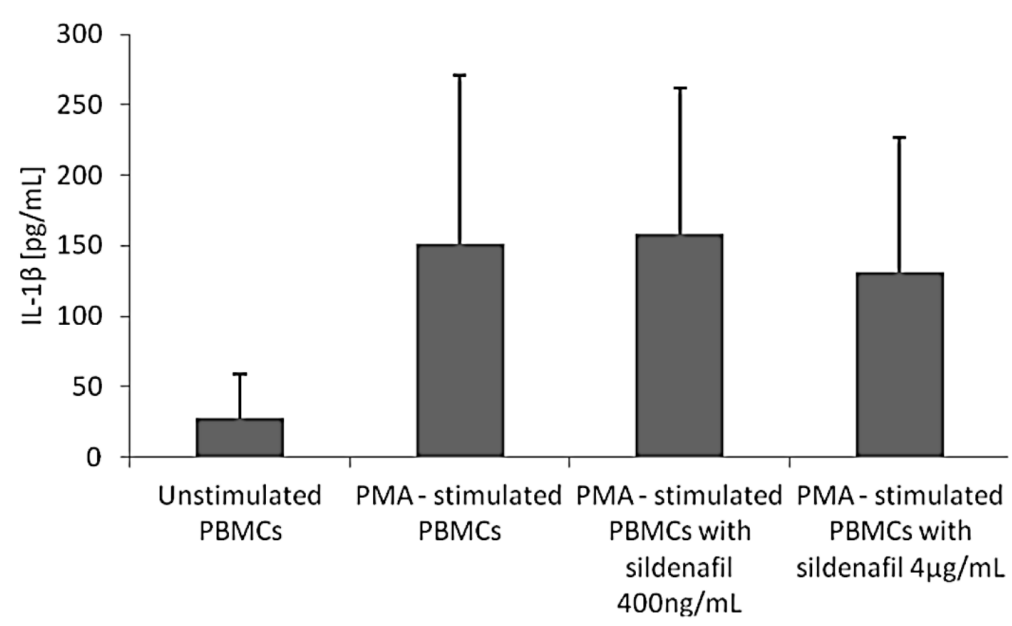

Figure 2. IL-1 $\beta$ concentration in peripheral blood mononuclear cells (PBMCs) supernatants measured by enzyme-linked immunosorbent assay (ELISA, mean \pm standard deviation) after incubation with sildenafil and with or without stimulation with phorbol myristate acetate (PMA) plus ionomycin. Differences were considered statistically significant when $\mathrm{p}<0.05$ for ANOVA test on 16 PBMCs samples

\section{Statistical analysis}

The results were expressed as mean +/- standard deviations (SD). Data were analyzed using Statistica (version 12). After testing all the data for normality (Shapiro-Wilk test), ANOVA test was performed to analyze the data. All obtained results were repeated with the Friedman test. A probability value of $\mathrm{p}<0.05$ with a $95 \%$ confidence interval was considered to indicate a statistically significant difference.

All experiments were approved by the Ethics Committee of Medical University of Warsaw (No. KB/164/2017).

\section{RESULTS}

To determine the effects of sildenafil on TNF$\alpha$, IL-1 $\beta$ and IL-6 production in PBMCs from healthy men, cells were incubated with $400 \mathrm{ng} / \mathrm{mL}$ and $4 \mu \mathrm{g} / \mathrm{mL}$ of the drug. PMA and ionomycin were used for PBMCs stimulation. Control variants were not stimulated.

\section{Sildenafil increases TNF- $\alpha$ release from healthy men PBMCs}

Addition of $400 \mathrm{ng} / \mathrm{mL}$ of sildenafil to stimulated PBMCs resulted in a significant increase of TNF- $\alpha$ production $(p<0.05)$. Sildenafil at both tested concentrations did not affect TNF- $\alpha$ production without stimulation. Concentrations of TNF- $\alpha$ in
PBMCs supernatants in different experimental conditions are shown in Figure 1.

\section{Sildenafil does not affect IL-1 $\beta$ and IL-6 release from healthy men PBMCs}

Sildenafil at both tested concentrations (400 $\mathrm{ng} / \mathrm{mL}$ and $4 \mu \mathrm{g} / \mathrm{mL}$ ) did not affect IL-1 $\beta$ and IL-6 production in unstimulated and PMA - stimulated PBMCs from healthy men. Concentrations of IL- $1 \beta$ and IL-6 in PBMCs supernatants in different experimental variants are shown in Figure 2 and 3.

\section{Sildenafil has no effect on PBMCs viability}

Cell viability was assessed by trypan blue staining. No significant difference in the response of control and sildenafil-treated PBMCs at either drug concentration tested was fund. The percentage of viable cells was $97 \% \pm 1.3 \%$ (range: $95-98 \%$ ) (Fig. 4).

\section{DISCUSSION AND CONCLUSION}

The aim of this study was to evaluate the effects of sildenafil on the production of pro-inflammatory cytokines (TNF- $\alpha$, IL-1 $\beta$, IL-6) by PBMCs from healthy men.

TNF- $\alpha$, IL-1 $\beta$, IL-6 are pleiotropic cytokines whose production is increased in most inflammatory conditions. Numerous studies suggest that these secreted proteins are potential therapeutic targets in many chronic diseases (11-13). 
In literature, there are reports suggesting that sildenafil regulates cytokine production in animal models. It was demonstrated that the drug's administration decreased serum levels of TNF- $\alpha$, IL- $1 \beta$ (14-16), interferon (IFN)- $\gamma$ and $\operatorname{IL}-2(16,17)$ in mice. In addition, it was shown that sildenafil increased the level of IL-10 (18). Karakhanova and colleagues (19) observed that sildenafil treatment had a tendency to decrease the percentage of $\mathrm{CD}^{+}$ and to increase the percentage of $\mathrm{CD}^{+} \mathrm{T}$ cells in mice. Moreover, the drug decreased the serum level of IL-6. However, the anti-inflammatory effects of sildenafil were not confirmed in a study of Tsai et al. (20) and Clayton et al. (21). In these studies, sildenafil did not inhibit TNF- $\alpha$, IL-4 and IL-5 production in mice. Thus, while most studies suggest that sildenafil downregulates pro-inflammatory cytokines release in animal models, some authors report opposite or inconclusive results.

Despite the fact that sildenafil is a widely used drug, only a few studies evaluated its role in the regulation of cytokine release in humans. Most studies were conducted on diabetic and ED patients. It was demonstrated that sildenafil administration in patients with type 2 diabetes reduced the level of IL6 (22) as well as the concentration of monocyte chemoattractant protein-1 (MCP1) and transforming growth factor- $\beta$ (TGF- $\beta$ ) $(23,24)$. Vlachopoulos et al. (25) evaluated the effect of sildenafil on proinflammatory markers in ED patients. The study demonstrated for the first time that this PDE5 inhibitor reduced the synthesis of fibrinogen, high sensitivity C-reactive protein (hsCRP), high sensitivity IL-6 (hsIL-6) and TNF- $\alpha$. Moreover, immu- nomodulatory effects of sildenafil were examined in women with recurrent abortion. El-Far and colleagues (26) investigated whether intravaginal sildenafil administration (4 times/day for 24 days) affected TNF- $\alpha$ and $\mathrm{CD}^{+}{ }^{+} \mathrm{CD}_{5} 6^{+}$natural killer cells (NKT cells). This group demonstrated that sildenafil reduced the percentage of $\mathrm{CD}^{+}{ }^{+} \mathrm{CD} 56^{+} \mathrm{NKT}$ cells and the concentration of TNF- $\alpha$ in peripheral blood. In contrast to the study of El-Far et al., Ohams et al. (27) observed that intravaginal administration of sildenafil during the proliferative phase of the menstrual cycle increased TNF- $\alpha$ serum levels in women with recurrent abortion. Several studies were also performed on human cell lines. It was demonstrated that sildenafil significantly decreased the level of Th1 chemokine CXCL10 in human cardiac cells as well as decreased circulating CXCL10 in patients with diabetic cardiomyopathy (28). The study of Kim et al. (29) showed that sildenafil downregulated IL-1 $\beta$ synthesis in a human synovial sarcoma cell line. Only a few studies evaluated the effects of sildenafil on the immune system in healthy humans. It was shown that sildenafil decreased IL-2 synthesis in T effector cells (Teffs) from healthy humans in vitro but had no effect on IL-4 and IL-13 production (17). In our previous study, we demonstrated that sildenafil downregulated osteopontin (OPN) production in healthy men PBMCs (9). Moreover, we showed that sildenafil significantly decreased the activity of NK cells, but had no effect on $\mathrm{T}$ and $\mathrm{B}$ cells proliferation and phagocytic activity of granulocytes (8).

The present study demonstrated that sildenafil had no influence on IL-1 $\beta$ and IL-6 synthesis in

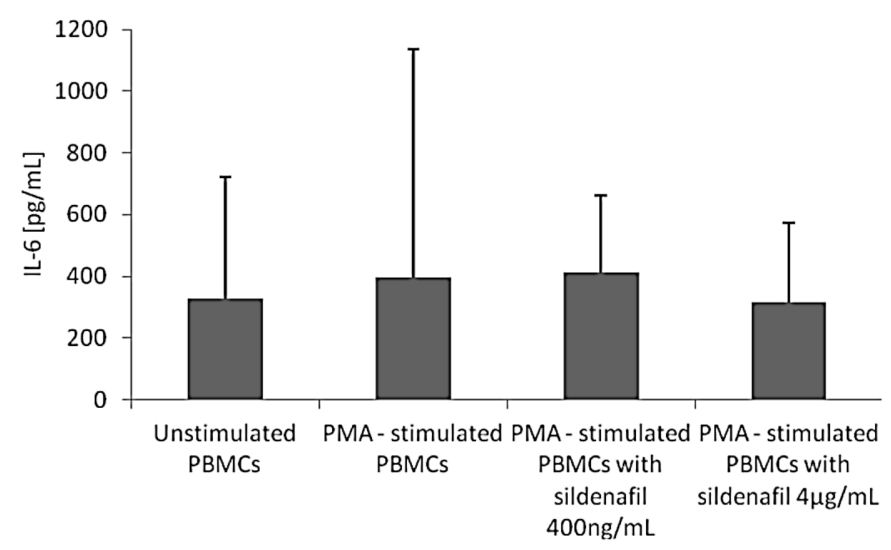

Figure 3. IL-6 concentration in peripheral blood mononuclear cells (PBMCs) supernatants measured by enzyme-linked immunosorbent assay (ELISA, mean \pm standard deviation) after incubation with sildenafil and with or without stimulation with phorbol myristate acetate (PMA) plus ionomycin. Differences were considered statistically significant when $\mathrm{p}<0.05$ for ANOVA test on 16 PBMCs samples 


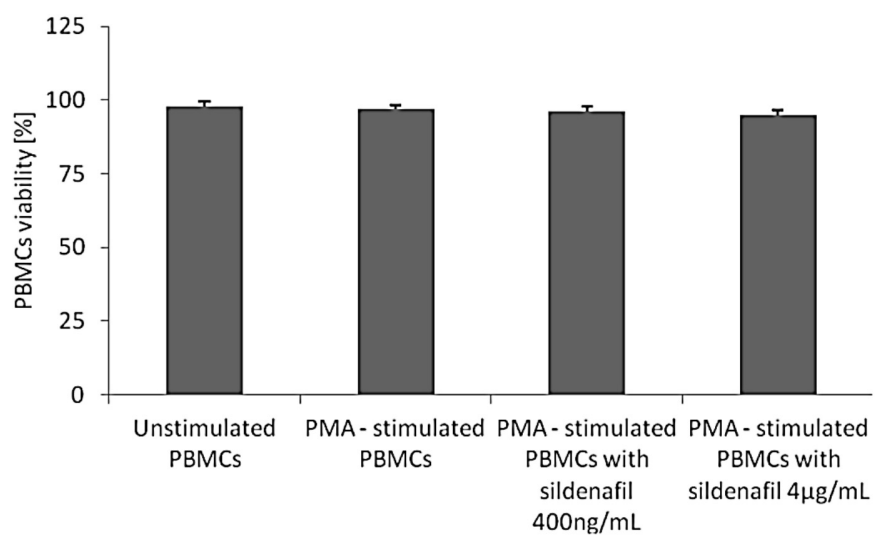

Figure 4. Effect of sildenafil on peripheral blood mononuclear cells (PBMCs) viability. Data are expressed as mean \pm standard deviation determined by trypan blue staining after incubation with sildenafil and with or without stimulation with phorbol myristate acetate (PMA) plus ionomycin. Differences were considered statistically significant when $\mathrm{p}<0.05$

PBMCs, however, this drug upregulated TNF- $\alpha$ production in healthy men PBMCs. These observations are consistent with the results obtained by Ohams et al. in women with recurrent abortion. To the best of our knowledge, this is the first report describing such effects of sildenafil.

As mentioned above, sildenafil increases NO levels by stimulating iNOS and triggering the phosphorylation of NOS (4). NO plays a role in neurotransmission, vasodilatation and immune modulation (30). Most of these effects are mediated through cGMP signaling pathway. However, it was demonstrated that NO acts by a cGMP-independent mechanism. It was revealed that NO increases TNF- $\alpha$ production in human PMA-stimulated PBMCs by inhibition of cyclic adenosine monophosphate (cAMP) (31).

Currently, sildenafil is the most effective therapy for ED (2). Sexual dysfunction is common in patients with cardiovascular diseases (CD) (32). There is increasing evidence that TNF- $\alpha$ plays an important role in both $\mathrm{CD}$ and $\operatorname{ED}(32,33)$. Moreover, TNF- $\alpha$ is a cytokine that has been implicated in the pathogenesis of multiple diseases. Stimulation of TNF- $\alpha$ synthesis may be disadvantageous for men with $\mathrm{ED}, \mathrm{CD}$ and some autoimmune diseases.

In conclusion, our results strongly suggest that sildenafil enhances TNF- $\alpha$ production in PBMCs from healthy men. This is the first report describing such effects of this drug. Therefore further studies, performed also in women, on the impact of sildenafil on TNF- $\alpha$ gene expression, as well as NF- $\kappa \mathrm{B}$ activation will be helpful to extend our knowledge about the immunomodulating role of sildenafil in humans.

\section{Acknowledgments}

This work was supported by intramural funds from the Medical University of Warsaw

\section{Conflict of interests}

The authors declare that they have no conflict of interest.

All procedures performed in studies involving human participants were in accordance with the ethical standards of the institutional and/or national research committee and with the 1964 Helsinki declaration and its later amendments or comparable ethical standards.

\section{REFERENCES}

1. Kohut M.L., McCann D.A., Russell D.W., Konopka D.N., Cunnick J.E. et al.: Brain Behav. Immun. 20, 201 (2006).

2. Boswell-Smith V., Spina D., Page CP.: Br. J. Pharmacol. 147 (suppl. 1), S252 (2006).

3. Liu X.M., Peyton K.J., Wang X., Durante W.: Biochem. Pharmacol. 84, 1045 (2012).

4. Kukreja R.C., Salloum F., Das A., Ockaili R., Yin C. et al.: Vascul. Pharmacol. 42, 219 (2005).

5. Kobayashi Y.: J. Leukoc. Biol. 88, 1157 (2010).

6. Essayan D.M.: J. Allergy Clin. Immunol. 108, 671 (2001). 
7. Kniotek M., Boguska A.: J. Immunol. Res. 2017, 4541958 (2017).

8. Boguska A., Kaleta B., Kniotek M., Górski A.: Acta Pol. Pharm. 75, 211 (2018).

9. Kaleta B., Boguska A.: Arch. Immunol. Ther. Exp. (Warsz). 65, 347 (2017).

10. Nichols D.J., Muirhead G.J., Harness J.A.: Br. J. Clin. Pharmacol. 53 (Suppl 1), 5S (2002).

11. Popa C., Netea M.G., van Riel P.L., van der Meer J.W., Stalenhoef A.F.: J. Lipid Res. 48, 751 (2007).

12. Ren K., Torres R.: Brain Res. Rev. 60, 57 (2009).

13. Srirangan S., Choy E.H.: Ther. Adv. Musculoskelet. Dis. 2, 247 (2010).

14. Yildirim A., Ersoy Y., Ercan F., Atukeren P., Gumustas K. et al.: Pulm. Pharmacol. Ther. 23, 215 (2010).

15. Zhao S., Zhang L., Lian G., Wang X., Zhang H. et al.: Int. Immunopharmacol. 11, 468 (2011).

16. Nunes A.K., Rapôso C., Luna R.L., CruzHöfling M.A., Peixoto C.A.: Cytokine 60, 540 (2012).

17. Pifarré P., Gutierrez-Mecinas M., Prado J., Usero L., Roura-Mir C. et al.: Exp. Neurol. 251, 58 (2014).

18. Raposo C., Nunes A.K., Luna R.L., Araújo S.M, da Cruz-Höfling M.A. et al.: Mediators Inflamm. 2013, 321460 (2013).

19. Karakhanova S., Yang Y., Link J., Soltek S., von Ahn K. et al.: Mol. Immunol. 56, 649 (2013).
20. Tsai B.M., Turrentine M.W., Sheridan B.C., Wang M., Fiore A.C. et al.: Ann. Thorac. Surg. 81, 272 (2006).

21. Clayton R.A., Dick C.A., Mackenzie A., Nagasawa M., Galbraith D. et al.: Respir. Res. 5, 4 (2004).

22. Aversa A., Vitale C., Volterrani M., Fabbri A., Spera G. et al.: Diabet. Med. 25, 37 (2008).

23. Giannetta E., Isidori A.M., Galea N., Carbone I., Mandosi E. et al.: Circulation 125, 2323 (2012).

24. Giannetta E., Feola T., Gianfrilli D., Pofi R., Dall'Armi V. et al.: BMC Med. 12, 185 (2014).

25. Vlachopoulos C., Ioakeimidis N., Rokkas K., Angelis A., Terentes-Printzios D. et al.: Int. J. Cardiol. 182, 98 (2015).

26. El-Far M., El-Motwally Ael-G., Hashem I.A., Bakry N.: Clin. Chem. Lab. Med. 47, 1433 (2009).

27. Ohams M., Jerzak M., Górski A.: Ginekol. Pol. 86, 520 (2015).

28. Di Luigi L., Corinaldesi C., Colletti M., Scolletta S., Antinozzi C. et al.: Inflammation 39, 1238 (2016).

29. Kim K.O., Park S.Y., Han C.W., Chung H.K., Yoo D.H et al.: Exp. Mol. Med. 40, 286 (2008).

30. Shimokawa H., Godo S.: J. Cardiovasc. Pharmacol. 67, 361 (2016).

31. Wang S., Yan L., Wesley R.A., Danner R.L.: J. Biol. Chem. 272, 5959 (1997).

32. Rodrigues F.L., Fais R.S., Tostes R.C., Carneiro F.S.: Curr. Drug Targets 16, 442 (2015).

33. Ferrari R.: Pharmacol. Res. 40, 97 (1999).

Received: 05. 04. 2018 